\title{
Learning How to Learn from Disasters through a Comparative Dichotomy Analysis: Grenfell Tower and Hurricane Katrina Case Studies
}

\author{
Maria Iglesias-Mendoza ${ }^{1}$, Akilu Yunusa-Kaltungo ${ }^{2, *(\mathbb{D}}$, Sara Hadleigh-Dunn ${ }^{1}$ and Ashraf Labib ${ }^{1}$ (1) \\ 1 Portsmouth Business School, Faculty of Business and Law, University of Portsmouth, \\ Portsmouth PO1 2UP, UK; maria.iglesias-mendoza@myport.ac.uk (M.I.-M.); \\ sara.hadleigh-Dunn@port.ac.uk (S.H.-D.); ashraf.labib@port.ac.uk (A.L.) \\ 2 Department of Mechanical Engineering, Aerospace and Civil Engineering (MACE), University of Manchester, \\ Manchester M13 9PL, UK \\ * Correspondence: akilu.kaltungo@manchester.ac.uk
}

\section{check for} updates

Citation: Iglesias-Mendoza, M.; Yunusa-Kaltungo, A.;

Hadleigh-Dunn, S.; Labib, A.

Learning How to Learn from

Disasters through a Comparative

Dichotomy Analysis: Grenfell Tower and Hurricane Katrina Case Studies. Sustainability 2021, 13, 2030. https:// doi.org/10.3390/su13042030

Academic Editor:

Amir Khorram-Manesh

Received: 29 January 2021

Accepted: 9 February 2021

Published: 13 February 2021

Publisher's Note: MDPI stays neutral with regard to jurisdictional claims in published maps and institutional affiliations.

Copyright: (c) 2021 by the authors. Licensee MDPI, Basel, Switzerland. This article is an open access article distributed under the terms and conditions of the Creative Commons Attribution (CC BY) license (https:/ / creativecommons.org/licenses/by/ $4.0 /)$.

\begin{abstract}
We describe two well-established, practice-based Master's programmes as examples of existing competence development opportunities for practitioners and how such links between theory and practice can be developed and taught within the Higher Education (HE) context. We hypothesise that learning from major failures is essential in linking theory with practice in both engineering and management education. We investigate how to train emergency response teams on coping with, and learning from, rare events; a major challenge to other practitioners in the fields of safety and risk management. Comparison is undertaken between two disasters-Hurricane Katrina in the USA and the relatively recent Grenfell Tower in the UK-using a balanced dual approach of paradoxes, a dichotomy. In this paper, we demonstrate the enhancement of both engineering and management education. This was achieved through using the two case studies to emphasize the relevance of incorporating advanced mental modelling approaches for root cause analysis in training and by comparing the two cases with respect to the black swan and black elephant concepts. It is recommended that future training has a balanced approach that encompasses the outlined features of dichotomies.
\end{abstract}

Keywords: learning from disasters; Grenfell tower; Hurricane Katrina; root cause analysis

\section{Introduction}

Sustainability is a very broad topic that covers virtually every aspect of human endeavours, which sometimes makes it difficult to have a single definition. Although not limited to these, it covers the management of the natural environment, built environment, well-being, raw materials, energy, people and knowledge [1-3]. Therefore, sustainability can be defined as a multifaceted endeavour aimed at enhancing the quality of life for people without necessarily compromising the integrity of their environments and the ability of future generations to meet their own needs [4]. While research and practice have continued to develop and implement useful strategies for preserving most of our most vulnerable resources, it is also crucial to note that such strategies cannot be truly sustainable without systematizing the ability of humans to learn from failures and successes. In this paper, we propose a framework for using a hybrid operational research approach to demonstrate learning how to learn from disasters. With a growing focus on linking theory with practice more explicitly in postgraduate courses, this paper seeks to explore one way that this may be addressed meaningfully. The recent Grenfell Tower Disaster (GTD) in London is a stark reminder that, despite the attainment of safety risk management proficiencies that most organisations and countries have achieved, it is still necessary to reflect upon whether safety management systems are adequately learning from previous occurrences $[5,6]$. In the field of disaster risk reduction, learning has been addressed in the literature from various 
perspectives. For example, learning through a participatory process for the community with respect to flood risk management [7], learning from crisis management exercises [8,9], learning from natural disasters $[10,11]$ and impacts on supply chain resilience [12], learning from disasters and their impacts on middle managers [13] and learning from humanitarian logistics for facility locations [14].

This paper makes a strong case for the possibility of developing a robust practicebased safety competence development framework for design engineers, safety regulators, operations engineers, process engineers, safety experts, firefighters, maintenance engineers, project engineers, accident investigators, prosecutors and risk and crisis managers through the harmonization of techniques currently taught within two Masters programmes in institutions based in the UK (Reliability Engineering and Asset Management (REAM) at the University of Manchester and Risk, Crisis and Resilience Management (RCRM) at the University of Portsmouth), into a single framework for continuously learning from disasters. Before embarking on the core argument and proposal of this paper, it is important to remind ourselves that the aftermath of high-visibility accidents [15], such as the Piper Alpha oil rig fire [16], Bhopal [17] and Chernobyl [16], are often associated with significant casualty tolls, financial losses and loss of community trust in existing or possible future initiatives [18-20], which eventually makes learning from disasters and crisis management a far more difficult activity.

An organisational crisis can be defined as an event perceived by managers and stakeholders as highly salient, unexpected and potentially disruptive [21]. The same authors who provided this definition have observed that research in this field remains fragmented but can generally be grouped into two primary perspectives: one focussed on the internal dynamics of a crisis and the other on managing external stakeholders. Whilst the former perspective is internally oriented toward the technical and structural aspects of a crisis, the latter perspective is externally oriented toward managing stakeholder relationships. Based on these premises, a strong case can be made that a balanced dual approach, in the form of a dichotomy (i.e., a division or contrast between two things that are, or are represented as being, opposed or entirely different), needs to be addressed when training practitioners in risk and crisis management, so as to maintain a "balanced" view of critical issues and challenges. By examining two well-established Masters programmes and then focusing on an analysis developed to investigate two major incidents as case studies, we conclude that training also needs to incorporate not only internal and external factors but also quantitative and qualitative analysis, technical and trust issues, and other dualities related to learning from disasters. Examples of such dichotomies are learning in both corrective and preventive modes; i.e., learning to mitigate and prevent versus learning from analysis and investigation into the aftermath of an incident. Another dichotomy example is learning from near misses versus learning from major failures.

It has long been argued that organizations can vicariously learn from others [22,23]. For example, when analysing the Deepwater Horizon disaster, it can be observed that it was more similar to the Apollo 13 disaster than to the Exxon Valdez disaster [24], in that it involved having to manage systems without human eyes on the scene. Using the same theoretical lens, one can also argue that the GTD in London is in many ways similar to the Hurricane Katrina Disaster (HKD) and its impact on the community in New Orleans because it involved social issues and trust between the government and the community. In this paper, we focus on comparing GTD with HKD, where both have been analysed using engineering failure modelling techniques and methodologies reported by Labib and Read [25]. The following section presents research works that are closely related to such dichotomies. In presenting the literature, we will try to relate, where possible, our reflection on how each aspect of the dichotomy studied can be applied to the GTD, which is the more recent case. 


\section{Review of Previous Literature}

Because of the balanced dual approach proposed in this paper, the literature review is divided into two parts. The initial part examines literature studies related to internal and external perspectives in crisis management, while the latter part deals with dichotomy in routines and procedures.

\subsection{Literature Related to Internal and External Perspectives in Crisis Management}

The first perspective by Bundy et al. [21] was labeled as the internal perspective and primarily focuses on the within-organization dynamics of managing risk, complexity and technology. The significance and relevance of this perspective were also echoed by other authors including Bigley and Roberts [26], Gephart et al. [27], Pearson and Clair [28], Perrow [29] and Starbuck and Milliken [30]. For these scholars, crisis management involves the coordination of complex technical and relational systems, as well as the design of organizational structures to prevent the occurrence of, reduce the impact of and learn from crises. In contrast, the second perspective, by Bundy et al. [21], labeled the external perspective, focuses on the interactions of organizations and external stakeholders, largely drawing from theories of social perception and impression management. According to this perspective, crisis management involves shaping perceptions and coordinating with stakeholders to prevent, solve and grow from a crisis and the resultant consequences (e.g., Bundy and Pfarrer [31]; Coombs [32]; Elsbach [33]; Pfarrer et al. [34]). By further reflecting on GTD, the alignment and relevance of both perspectives becomes more intense. For instance, the emerging issues regarding cladding and testing of materials against fire resistance can be associated with the internal perspective, while the issues of trust between victims and authorities are external and are the main issues being covered in the GTD investigation so far. There is hence a need for more research into approaches that can facilitate clarity around decision-making by various agencies to increase trust about intervention [35-39] and also clarity about translations into different languages [40].

\subsection{Literature Related to Dichotomy in Routines and Procedures}

Organizations' routines have been researched in terms of dichotomies, such as exploitation of new possibilities and the exploration of old certainties in organizational learning [41]. They have also been researched as a dichotomy, or duality, of stability and change and compared in terms of their mechanism and outcome [42]. In one instance, D'Adderio [43] proposed a dichotomy of (re)framing, in the form of prescribing actions, and overflowing, in the form of interpreting rules and procedures. Feldman and Pentland [44] on the other hand adapted a taxonomy for routines that was originally conceived by Latour [45] in his analysis of power and proposed a dichotomy that shapes routines in terms of the ostensive aspect of a routine (which relates to the principal structure) and the performative aspect (which relates to its specific contents in terms of practice and implementation). Levinthal and Rerup [46] studied the categorisation of routines in terms of the dichotomy of mindful and less mindful processes and suggested that the ostensive/performative classification is useful for understanding the two processes. There are always interactions and interdependent issues in a real and complex situation. Hence, the authors who proposed these dichotomies (exploitation and exploration, stability and change, behavioural and cognitive, ostensive and performative, concrete and abstract, framing and overflowing, mindful and less mindful) have also pointed out that there is a degree of feedback, interaction, complementary relationships and recursive relationships between the components of these dichotomies. The same applies to knowledge management in terms of the dichotomy of tacit and explicit knowledge as proposed by Nonaka and Takeuchi [47], as well as the transformation process among and between them.

In the GTD, there was a clear problem with routines and procedures, based on the premise that residents were initially instructed to stay in their apartments during the early stages of the fire (which is part of the standard and accepted routine for such buildings). However, now we know that this routine is designed to cope with fires from inside the 
building, rather than fires from outside. We also know that residents who ignored this instruction managed to escape the fire. This is quite similar to the case of the Hokuriku tunnel train fire that occurred in Japan in 1972, which claimed 30 lives and injured many others [48]. On this occasion, the train driver was obeying the regular emergency routines that specified that drivers should immediately stop trains once the control panel provides an indication of fire in any wagon, in order to minimise cascading effects to other wagons due to the effects of wind during train motion. However, we now know that if the driver had continued to travel outside the tunnel rather than stopping as per the routine, many passengers in other wagons would have survived rather than suffocating in the tunnel. This and many other examples show the importance of applying "common sense" or "operational discretion" in conjunction with standard operating procedures, as well as the need to understand both the ostensive and performative aspects [49,50]. Such common sense has been theorized as "mindfulness" in the literature that relates to high-reliability organisations [51] and has also been modeled as a maturity framework [52].

Another dichotomy of routines is in the form of reliance on both working and procedural types of memory. Under stress, the human ability to access higher cognitive resources is significantly reduced. This phenomenon was investigated in studying the AF447 accident [53], where, despite the existence of a good design and clear recovery procedures in an Airbus, a degradation in flight automation required increased human cognitive input. This work led to proposing a set of suggestions for pilot training, which focused on developing core flying skills with less reliance on computers and the technology in the cockpit. The same authors agreed with Markman et al. [54] that the influence of pressure on task performance indicates that tasks that rely heavily on working memory are easily hampered by pressure, while tasks that rely mainly on procedural memory tend to be performed better under pressure.

Research by de Wit and Cruz [53] argues that when recovery procedures are frequently rehearsed, they gradually turn to procedural memories and no longer rely so heavily on working memory, and that this effect is greatly enhanced by training under pressure. However, we argue that such procedural memory in its extreme becomes a "programmed" attitude, which may be an obstacle to common sense. In other words, training also needs to incorporate cases where one can identify situations where existing routines are no longer applicable.

\section{Revisiting Reported Findings and Sequences of Events for the Selected Case Studies}

Much has been reported with regard to the events that led to the occurrence of our case study disasters, including their direct and indirect consequences. However, we think it necessary to provide a brief overview for readers to relate more deeply with the failure analysis conducted in the subsequent sections. This approach also enables this paper to be read as a standalone piece of work. The rationale for selecting the GTD and HKD case studies is that they are excellent examples of failure events with some similarities, whilst their complexities make them worthy of analysis through the proposed framework.

As mentioned earlier, this paper makes a case for the possibility of developing a robust practice-based safety competence development framework for different disciplines within both engineering and management fields. Although both case studies are different in nature, at a certain level of analysis, there are generic lessons that are common to both of them as well as common with other types of disasters. This same argument caused the chapters of the work on learning from failures [55] to be organized according to the alphabetic order of the cases (hence the term A to Z). This is considered a good practice, rather than compiling case studies that belong to a certain discipline or certain decade, as the hypothesis was that lessons can be learnt from a generic nature perspective that cuts across different disciplines. Such a multidisciplinary approach in learning from case studies permits the incorporation of different and balanced views, as well as minimization of inclusion of unrealistic assumptions. 


\subsection{Case 1: Grenfell Tower Building}

Grenfell Tower is a residential building that was built between 1972 and 1974. It has 24 storeys containing 120 units of social housing, located within the very affluent Borough of Kensington and Chelsea in London (with a staggering average annual income of $£ 116,000$ and where the average cost of homes is $£ 2$ million). Despite the many housing units contained in Grenfell Tower, the building design is limited to a single stairwell and lacked fire arrest systems such as sprinkler systems. Between 2014 and May 2016, the Kensington and Chelsea Tenant Management Organization (KCTMO), through Rydon Construction, performed a significant renovation of the Tower, estimated at approximately $£ 9$ million, to improve its appearance and thermal insulation [56,57]. Some of the major aspects of this renovation activity involved the installation of new windows, heating systems and, most significantly, the installation of aluminium insulation cladding on the exterior of the building, which was made of a flammable material. The decision to install relatively flammable aluminum panels, instead of more fire-retardant zinc panels, was allegedly motivated by the cost-saving of nearly GBP 300,000 [58].

\subsubsection{Overview of the GTD Sequence of Events}

According to a report by the World Health Organization (WHO), more than 300,000 people die from fire-related incidents around the world annually $[59,60]$. Whilst most of those deaths are associated with developing countries where reliable rescue services are limited, a significant number of residential fire disasters still occur in advanced economies. For instance, a study by Jonsson et al. [61] revealed that residential fires account for the highest number of fatalities related to fires in Sweden. Similar studies by Mulvaney et al. [62] and Tannous et al. [63] reiterated that more than 10 million disability-adjusted life years are lost annually to fire-related injuries. In addition to fatalities directly linked to residential fires, there is also the risk of additional injuries or deaths that may arise as a result of the reconstruction of such buildings, since the construction industry is one of the most hazardous industries [64]. While several organizations, as well as the countries in which they are domiciled, have made commendable advancements in safety management, these worrying statistics show that the journey to self-actualization in health and safety is far from complete.

Because the GTD is relatively recent and investigations are still ongoing, the details provided in this article are based on preliminary reports that are available in the public domain. Such sources of information are not limited to, but include, the study conducted by [56] on the relevance of the disaster for construction project team members. Hayes [65] highlighted the importance of noting both pleasant and unpleasant lessons that might emerge from the GTD, particularly identifying that man-made disasters do not occur at random but instead involve several individual but related failures (i.e., causal relationships). Watt [57] examined the disaster from the viewpoint of avoidable and unacceptable health inequalities. Irrespective of the viewpoint, the fundamental teaching from these studies is the criticality of collectively learning from such events, including their similarities with previous occurrences, no matter how unpleasant, to create very robust learning from disasters framework.

On June 14th, 2017, at 00:54 am, a faulty fridge-freezer caused a fire in the kitchen of a fourth-floor apartment of the Grenfell Tower, triggering several emergency phone calls. The first set of fire engines were in attendance within six minutes of the first emergency call, and reports specified that it took just $20 \mathrm{~min}(01: 14 \mathrm{am})$ to get the fire in the kitchen under control. However, although the internal fire source was under control, the fire had rapidly spread externally, towards the upper side of the building, melting the flammable insulation material. In less than thirty minutes, the whole building was on fire. No fire alarm alerted the residents. and at the same time, residents were instructed to remain indoors and shut their respective apartments as a part of a standard fire response routine. Some residents attempted to defy this instruction and tried to evacuate, but the only 
stairwell in the building was filled with thick black smoke, due to a lack of sprinkler systems. Two hundred firefighters attended to the fire, which burnt into the next day [56].

\subsubsection{Overall Analysis of the GTD}

Based on the contents of preliminary reports, including those provided in the works of Winstone [56], Hayes [65] and Watt [57], analysis of the disaster revealed the following direct consequences:

- Seventy-two residents died.

- Whilst there were hundreds of firefighters at the scene of the fire, they were unable to save more lives because of access restriction to and from the building (the only stairwell was filled with smoke), as well as the speed and intensity of the fire.

- The reliability and structural integrity of the fire doors within the Tower was unknown. The residents were legally responsible for fire doors, and only a limited number had been tested for fire resistance by block managers.

- There were no sprinkler systems in the building, as they were judged to be too expensive to install and test (GBP 200,000).

- There were potential indications of a failed emergency response policy, as residents were asked to remain in their apartments. This was further compounded by a combination of fire speed, intensity and lack of functionality of some of the fire doors.

- There was no functional central fire alarm system in the building.

- A positive consequence is in terms of health and safety in house building, and according to the Social Housing Barometer 2018, "Almost half of housing association now place health and safety as a top-five risk" [58]. Therefore, UK housing associations have increased investments in health and safety and fire risk reduction. However, there is still a long way to go, as there is evidence of lack of sprinklers in a significant number of London high-rise council blocks [66].

\subsection{Case 2: HKD and Sequence of Events}

HKD occurred between the 24th and 29th of August 2005, the 11th storm of the 2005 hurricane season. The storm hit the southeast USA around the Gulf of Mexico. During the initial stages of the storm on the 24th of August 2005, it was judged to be a Category 3 storm but later intensified to become a Category 5 storm during the early hours of the 28th of August. The hurricane produced a storm surge with waves $6 \mathrm{~m}$ above mean seal level, heavy rainfall and peak wind speeds of $278 \mathrm{~km} /$ hour. On August 26th, the states of Louisiana and Mississippi had activated their emergency response plans (ERPs) and implemented coastal evacuation plans. After the evacuation order, approximately 1.2 million inhabitants left the area, mostly to states bordering Louisiana.

Analysis of the HKD

Analysis of the disaster, based on several reports $[25,67,68]$, revealed the following direct consequences:

- There were 1100 fatalities reported.

- The cost of the hurricane was estimated to be $\$ 300$ billion.

- The US government provided $\$ 50$ billion worth of aid, although $\$ 1$ billion designated for victims of the hurricane was lost to fraud.

- Approximately 1 million people were rendered homeless as a result of damage to more than 800,000 housing units.

- Other impacts of the disaster included heightened vulnerability of people living under unsafe and violent conditions, as well as increased crime rates, which prompted the deployment of the US military and National Guard.

- Oil facilities were damaged, which produced a set of knock-on effects on oil scarcity and price hikes in the USA and UK.

- New Orleans lost most of its defences and could not cope with the hurricane's impacts. Approximately $80 \%$ of the city was immersed in up to $6 \mathrm{~m}$ of water. 
- Even after the flood defences were fixed, much of the city remained flooded with water for several months after the hurricane because many pump stations were disabled by the storm.

The HKD was the costliest storm in the history of the USA and one of the most deadly. There is a general consensus that the management of the HKD was ineffective and disorganized [25].

\section{A Comparative Dichotomy Analysis of HKD versus GTD}

Studies such as that by Yunusa-kaltungo et al. [69] have been routinely published to investigate the causes of accidents and possible means of averting future reoccurrence. While these studies generate invaluable contributions to the existing body of literature, they are often mono-directional (i.e., solely based on either qualitative or quantitative tools). In this section, we demonstrate the significance of developing a "learning from disasters framework" that incorporates both quantitative (engineering) and qualitative (management) classes, so that safety risk assessors, risk managers, designers and first responders, particularly firefighters, can better evaluate all facets of the disaster management. In order to achieve this, we have selected two groups of tools: fault tree analysis (FTA), reliability block diagram (RBD) and black-swan-black-elephant (BS-BE) analysis. FTA and RBD represent the engineering perspective, while BS-BE represents the management perspective.

\subsection{Reliability Engineering-Based Models for Learning from Disasters}

FTA is a gradual "top-down" approach for evaluating the causes of failure. It applies the principle of deductive logic, whereby an unwanted event (i.e., the "top event") is systematically broken down into its elemental causal factors (i.e., "basic events"). In addition to generating the root causes of the top event, fault trees (FTs) also use logic gates to depict a graphical representation of the causal relationships, which helps analysts understand the intricacies of complex failure mechanisms. FT development commences with the selection of the "top event" to be studied (which is often based on the criticality of such events), after which the contributing factors are gradually connected to it using logic gates. There are several logic gates applicable in typical FTs, such as AND, OR, NOT, k-outof-n, exclusive OR, inhibit and priority AND. However, AND and OR gates are the most versatile since they can be conveniently used to simplify most real-life systems. Hence, only AND and OR gates were used to develop the hierarchical structure of the causal factors relating to the case studies examined in the current study. The FTA has been widely used in risk assessment, either on its own or as hybrid with other techniques [70-72].

To better understand the practical applicability of the tool, the FTA in Figures 1 and 2 are used to depict the similarities between the causal factors that preceded the chosen case studies, which enables analysts to examine their similarities, thus learning from failures (LFF) [73] or learning from the disasters. With the exception of incident-specific basic events, such as a1-a8, a10-a11 (for GTD) and b1-b6, b8-b9 (for HKD), this comparison of the FTs representing both case studies clearly indicates the existence of significant similarities between several basic events (i.e., a9, a12, a13, b7, b10, b11, b12), particularly those associated with evacuation or residents, emergency preparedness and decision-making, which further confirms the relevance of the proposed learning from disasters approach. 


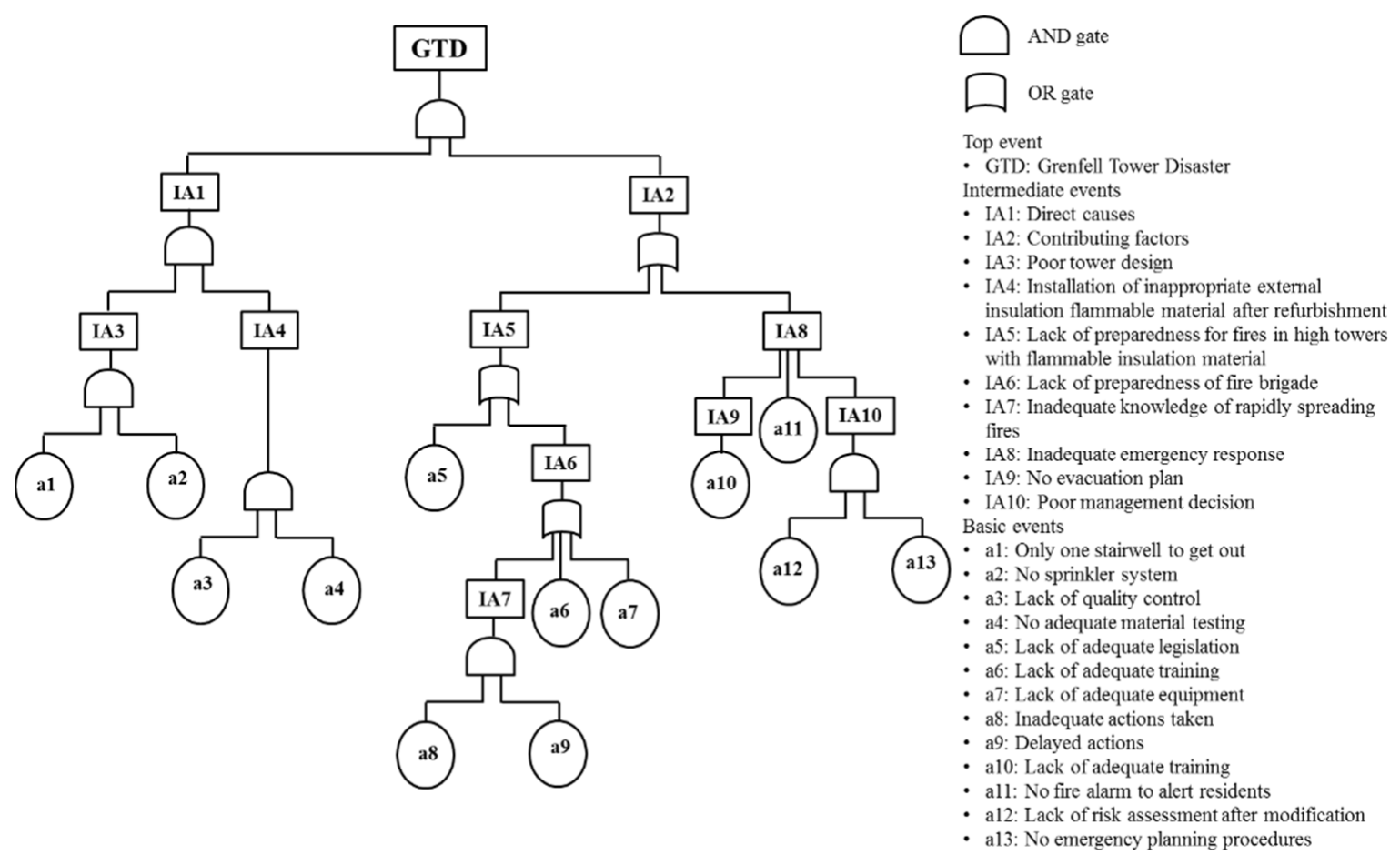

Figure 1. Grenfell Tower Disaster (GTD) fault tree.
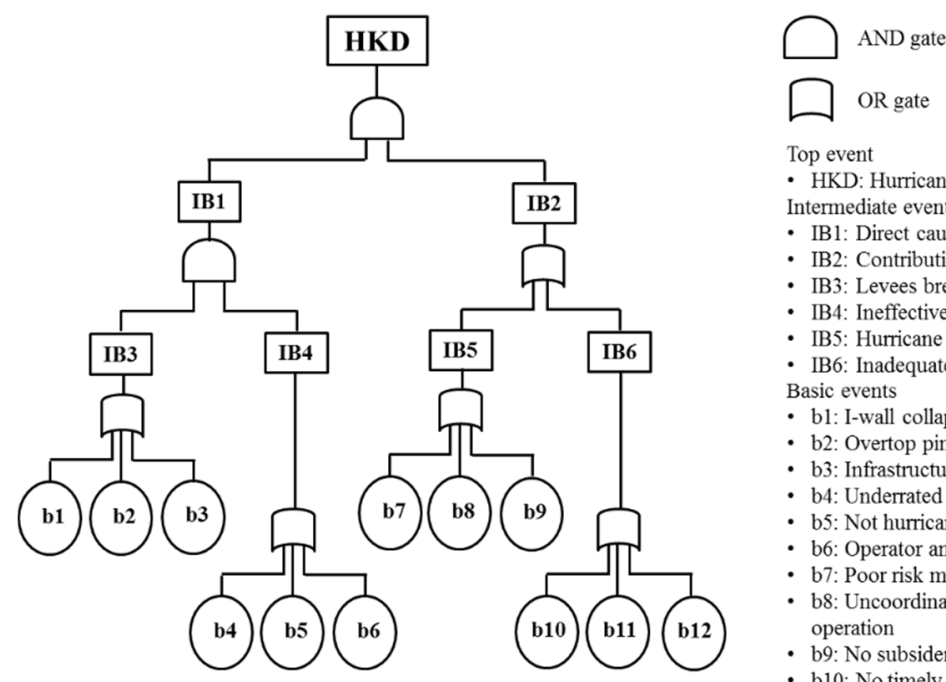

Top event

- HKD: Hurricane Katrina Disaster

Intermediate events

- IB1: Direct causes

- IB2: Contributing factors

- IB3: Levees breeched

- IB4: Ineffective pumping stations

- IB5: Hurricane protection management policy

- IB6: Inadequate emergency response

Basic events

- b1: I-wall collapse

- b2: Overtop ping

- b3: Infrastructure breeches

- b4: Underrated capacity

- b5: Not hurricane resistant

- b6: Operator and power dependant

- b7: Poor risk management

- b8: Uncoordinated construction, maintenance \&

operation

- b9: No subsidence correction

- b10: No timely mandatory evacuation

- b11: Unprepared local and state agencies

- b12: Late national response

Figure 2. Hurricane Katrina disaster (HKD) fault tree.

Because the fault trees for most real-life events often generate very complex structures that may be difficult to visualize in isolation, the approach adopted here was to convert each FT into an equivalent RBD using the following guiding principles [74] so that system vulnerabilities can be more easily visualized:

- Every "OR" in an FTA is a series configuration in the equivalent RBD.

- Every "AND" in an FTA is a parallel configuration in the equivalent RBD.

- Only model basic events, so the number of basic events in an FTA is equal to the number of boxes in the RBD.

- $\quad$ The order in an RBD does not matter. 
The equivalent RBDs shown in Figures 3 and 4 present a very fragile interaction between the different events, owing to the high number of series connections. Just as in the case of FTA, most of the series connections are associated with evacuation of residents and emergency response, which make these crucial areas of the study. The RBD analysis offers an insight into the vulnerabilities of the system being studied. It can be visualised as an advanced version of the classic Swiss Cheese Model (SCM). The simplicity and elegance of the SCM facilitates training about errors and defences and helps to conceptualise safety barriers (or the lack of them). However, the SCM has been criticised in terms of its way of representing failures; for example, it is not clear how the holes in the cheese line up, nor is the relationship between the holes clear. The RBD boxes in parallel, as shown in Figure 3, are equivalent to the cheese in the SCM model (safety barriers), and the boxes within each branch correspond to the holes within each barrier. Cut sets, which are defined as any group of boxes in the RBD (which, if all occur, will cause the top event in the FTA to occur), correspond to the alignment of a ray of light in the SCM model.

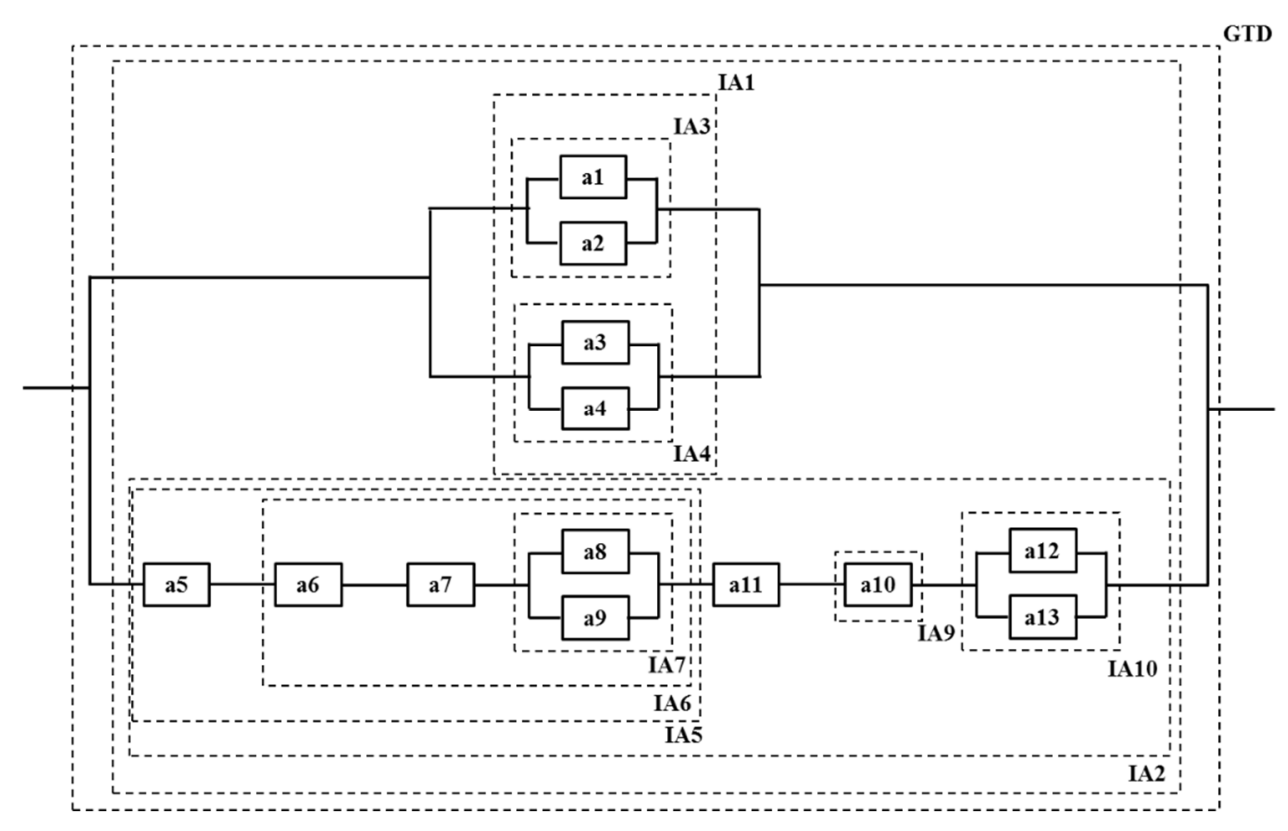

Figure 3. GTD equivalent reliability block diagram (RBD).

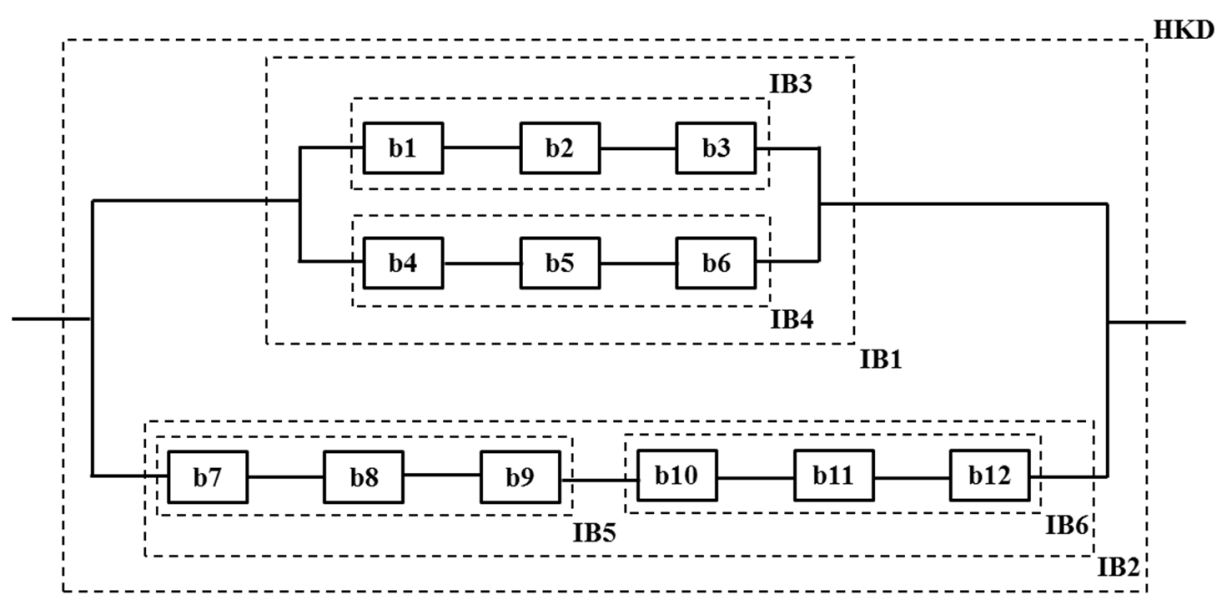

Figure 4. HKD equivalent RBD. 


\subsection{Management Based Models for Learning from Disasters}

Prior to the occurrence of GTD in 2017, there had been several instances of flammable cladding fires internationally. For instance, similar incidents occurred in Beijing (2009), Shanghai (2010), Dubai (2012) and France (2012). It would be expected that this record of cladding fire occurrences in several major cities would have provided a risk knowledge base, as well as preparation time for risk mitigation. Furthermore, London, Ronan and Teeuw [75] had highlighted many fire risks associated with high-rise buildings. However, it appears that few lessons were learned from previous incidents or associated publications.

While the GTD and HKD cases appear similar with regard to inadequate evacuation of residents and emergency response mechanisms, they also possess certain peculiarities that can be further explained using the black swan (BS) and black elephant (BE) concepts. A study by Taleb [76] provided a simplified but comprehensive means of differentiating BS and BE. BS is a term used to describe an event that occurs as a surprise, which is often associated with characteristics such as rarity, extreme impact and retrospective predictability. Conversely, BE signifies a known event that was ignored [76]. Based on these narratives, HKD and GTD can be respectively represented as BS and BE. Table 1 provides a more detailed description of the fundamental characteristics of BS and BE [77-82].

Table 1. Summary of similarities and differences between BS and BE.

\begin{tabular}{|c|c|}
\hline Black Swan (BS) & Black Elephant (BE) \\
\hline High-impact event that is beyond expectation & High-impact event that is beyond expectation \\
\hline Completely unpredictable except in hindsight & $\begin{array}{l}\text { Many know about it based on existing evidence, but often } \\
\text { ignored it because everyone is reluctant to deal with it }\end{array}$ \\
\hline Unknown unknowns or beyond hypothetical assumptions & Known unknowns \\
\hline Unimaginable and only known after the event & Imaginable and widely predicted by experts \\
\hline Triggers thoughts about theories and key concepts & It is an event that changes everything \\
\hline Shows severity of crisis & $\begin{array}{l}\text { Shows severity of crisis, as well as necessitates actions that often } \\
\text { lead to new measures/legislation }\end{array}$ \\
\hline Minimises the sense of threat of unexpected emergency events & Includes perception of facing a major problem \\
\hline
\end{tabular}

Despite the high impacts of both events, a combination of the narratives postulated by BS-BE and FTA-RBD analyses make it reasonable to classify HKD as unpredictable/unimaginable and GTD as predictable but ignored. Such narratives make a significant difference in the handling of incidents, although it is still very common for fieldbased experts to misconstrue one for the other. In an attempt to better clarify the reason why people act differently under BS and BE scenarios, previous studies questioned the ability of people to act rationally when confronted by information about risks, particularly those with low probabilities of occurrence $[79,83]$. For instance, events such as the GTD nearly always lead to legislation changes and the development of new policies, which is associated with a need for competency enhancement. It is also crucial to note that not all failures refer to disasters. A failure can be managed with a good emergency response plan, good preparedness and good crisis management, building resilience. Figure 5 shows the characteristics of BS and BE with regard to expectations and severity assessments, to assist policymakers in prioritizing their prevention and emergency response strategies. 


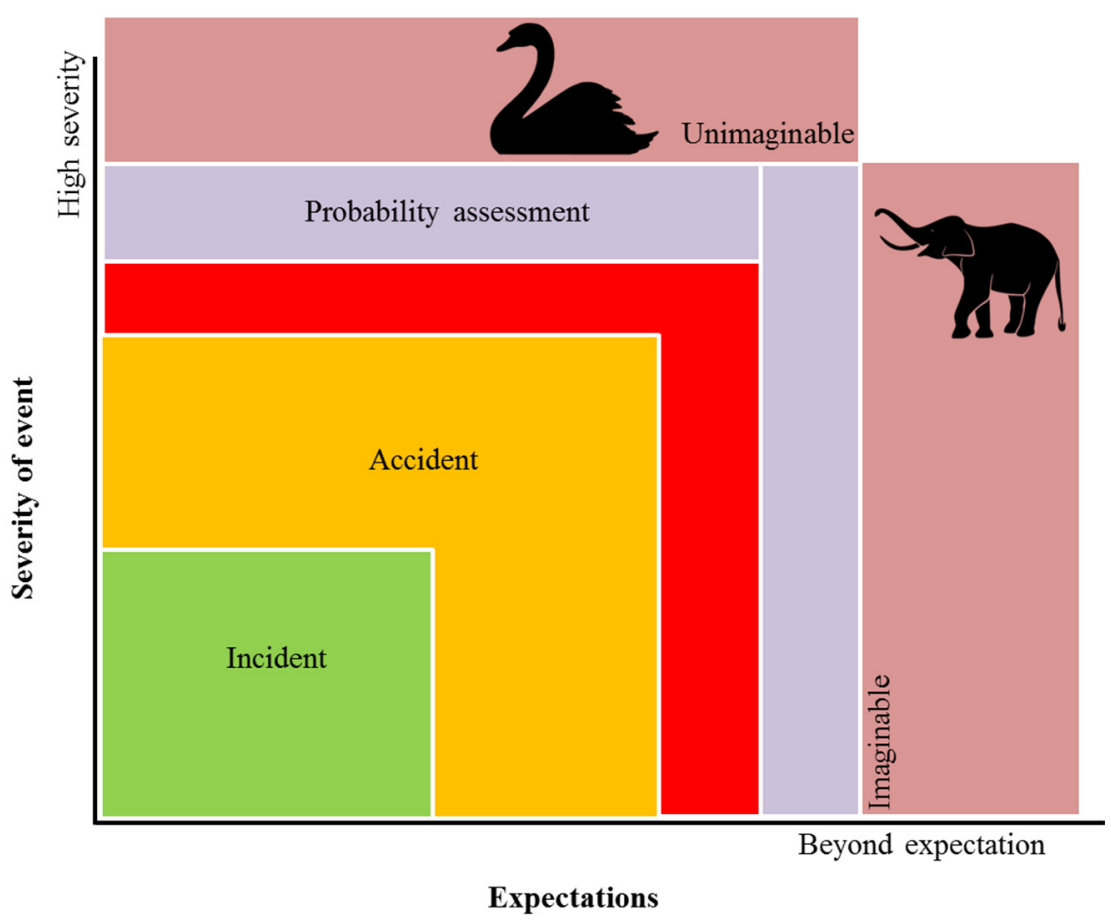

Figure 5. Relationship between expectations and severity of events based on black swan (BS) and black elephant (BE).

\section{The Need for a Harmonized Case Study Based Learning from Disasters Training Approach}

Several studies have indicated that the majority of failure causal factors are directly linked to risk management competence, which further emphasizes that the competence, attributes, skills and knowledge of designers, engineering failure analysts, prosecutors, risk assessors, first respondents, etc., are critical to learning from disasters [16,84,85]. For instance, a portion of the independent review report on building regulations and fire safety clearly states that "numerous examples have been quoted, demonstrating lack of competence among designers, builders, fire engineers, fire consultants, fire risk assessors, building control inspectors and others, which compromises the fire safety of buildings" [86]. Whilst it is undeniable that organizations are incurring huge expenses in relation to the professional development of their employees annually, some questions remain about how much of these initiatives are converted into field experience. A workplace survey by Rowden [87] indicated that as much as $\$ 230$ billion is spent every year on formal, informal and on-the-job training, but it remains unclear whether the knowledge acquired is adequately connected to the context of professional practices. This is something that both Masters programmes considered below actively seek to address.

In this section, we present two examples of existing Masters programmes that the co-authors of this study are involved with. The first focuses on risk, crisis and resilience management (RCRM), while the second relates to reliability engineering and asset management (REAM). In the RCRM programme, the underlying theory of "learning loops" is embedded within each session, which aims to support the approach described by several authors $[15,88]$ in their study of teaching accident causation and prevention. In doing so, we provide a demonstration of how training and development can be implemented in a more systematic approach through the provision of work-based training schemes as proposed by Becher [89] and operationalizing "learning how to learn" as proposed by Whitston [90].

The fulcrum of the RCRM course is the conversion of theory to practice. Case study learning is embedded within every module, highlighting the multi-disciplinary nature of risk. This allows students to deeply reflect on the causes of failure and consider best 
practices, as well as identify lessons learned for future resilience [91-95]. The diversity of the student cohort, with regard to the level of industrial experience and discipline (e.g., emergency services, military, oil and gas, financial services, project management, engineering, general consulting, healthcare), offers many opportunities for simulating real-life crisis scenarios. During the programme, students perform role-plays based on a multiple case study approach, managing a given "crisis" as it unfolds from the perspective of the roles they have assumed. The choice of case studies is often driven by the severity of the event and contemporaneity, exposing the students to multiple perspectives [96]. Typical examples of such pairs include:

- Piper Alpha, and Deepwater Horizon (oil and gas)

- $\quad$ Air France AF447 and German Wings (aviation)

- VW Emissions Crisis and Toyota Recalls (car manufacturing)

- Three Mile Island and Fukushima (nuclear power generation)

Although the REAM programme is more directed towards creating engineering solutions, its structure, teaching approach and cohort diversity are very similar to RCRM, which makes harmonization very realistic. Techniques such as failure modes effects analysis (FMEA), reliability-centred maintenance (RCM), FTA, RBD and condition-based maintenance (CBM) that provide useful insight into Engineering Failure Analysis (EFA) are at its core. In our proposed style of dichotomy analysis, we believe that in an ideal world, practitioners should be familiar with the main contents from the disciplines of management and engineering, in order to create a balance between qualitative and quantitative analysis $[23,83,97,98]$.

\section{Discussion and Major Lessons Learned}

Here we discuss major lessons learnt in Higher Education at strategic and operational levels. In this era of dynamism and uncertainty, strategic-level decisions that encompass robust practical knowledge of reliability engineering and crisis management are becoming increasingly important for preventing, and in extreme cases minimizing, the consequences of system failures. Hence, an important balance in designing Masters programmes should be geared towards achieving such a balance of a set of dichotomies in terms of engineering and management, technical and social, quantitative and qualitative, and positivist and interpretivist approaches, and emphasis on both single-loop and double-loop learning. In general, both success and failure offer good lessons for continuous improvement within all disciplines [36-39,73], although most conventional teachings are more inclined towards emphasizing the significance of learning from organizational successes $[99,100]$. However, some studies [101-103] are shifting this paradigm through their argument that the consequences of failures (especially catastrophic failures) are more likely to linger far longer than those of success, which eventually sets the framework that breeds experiential learning $[25,55,104]$. We also argue that a balance between a relatively recent case study and an older one provides a good balance in terms of learning. On the one hand, the recent cases tend to be more relevant and timely, but there are uncertainties about factual evidence as new evidence may appear later. On the other hand, older case studies have the advantage of being "classical cases" where the dust has settled; hence, generic lessons can be clearly demonstrated using the proposed techniques in a convincing argument.

At an operational level, this paper has reviewed, compared and discussed the Hurricane Katrina and Grenfell Tower case studies. Both disasters are complex events that require multi-disciplinary analyses from several teams and organizations. In both cases, prevention and preparedness are crucial steps that offer cost-effective means of incident control. Through a combination of reliability engineering and crisis management tools such as FTA, RBD and BS-BE, this study shows the feasibility of creating generic learning from a disasters framework that can serve as a training resource for a diverse range of field-based experts. Despite the existence of some event-specific failures, it is clear that the most significant failures for both case studies are similar, relating to the evacuation of 
residents and emergency response. The specifics of these failure points as related to the case studies are summarized below.

\subsection{Evacuation of Residents}

Owing to the lack of fire alarms within Grenfell Tower, some of the residents had to call the emergency services to ask what they should do. Preliminary reports and testimonies show that residents were told to stay inside their flats and wait for the firefighters to rescue them. In the UK, this is a standard policy for fires in high-rise tower blocks such as Grenfell Tower. However, a combination of refurbishment using flammable materials, as well as the occurrence cladding-related high-rise building fires elsewhere, should have triggered a modification of the evacuation policy for Grenfell Tower. Similarly, evacuation during HKD was a very slow process, such that as many as 100,000 inhabitants were not evacuated. This group comprised mainly the most vulnerable and poor who had no means of self-transportation.

\subsection{Emergency Response}

In the case of GTD, we appreciate that residents were not prepared to evacuate the building and no training was given regarding evacuation in that context. The dual effects of a single stairwell and the lack of sprinkler systems in the building led to the accumulation of black smoke along the only escape route. Some of the complaints from firefighters were that they did not know what to do under such a peculiar case of rapid cladding-fueled combustion, as they had never been trained under such scenarios. The fast-spreading fires in residential buildings with external combustible cladding are a challenge for emergency services, fire brigades and crisis management teams and require updated contingency plans and updated training.

\subsection{Unlearning from Failures}

When one examines fire disasters in towers and the issues of cladding, and the "stay-put" routine, it is clear that GTD demonstrates that the "unlearning from failures process" $[105,106]$ has occurred here as well. According to a BBC documentary, "On 14 June 2017, televisions across the country showed a west London tower block burn. For some, this was history repeating itself-as if five similar fires had simply not been important enough to prevent the deaths of 72 people in Grenfell Tower" [107].

The five similar fire incidents related to towers in the UK are listed below:

- Summerland-1973-Douglas, Isle of Man

- Knowsleys Heights-1991-Liverpool

- Garnock Court-1999-Scotland-clad for decorative reasons

- Harrow Court-2005-Stevenage

- Lakanal House-2009_Camberwell/South London

The following list summarizes relevant recommendations after enquiries:

a. After incident 1 (1973)-Recommendation: installation of sprinklers in all buildings.

b. Between incidents 1 and 2 (1973-1991, Margaret Thatcher's government):

- $\quad$ Reduced Fire Regulations from 300 pages to only 18 pages.

- $\quad$ Produced Approved Document B in the UK Fire Regulations: after this, cladding in buildings did not have to be fireproof.

c. After incident 3 (1999)—Recommendation: no use of cladding flammable material in high-rise blocks:

- Committee Final Report: decided that Approved Document B was sufficient.

- $\quad$ Fitting sprinklers in all high-rise accommodation buildings was rejected.

- The stay-put policy was rejected.

d. Between incidents 4 and 5 (2005-2009): Approved Document B was amended in 2006, allowing combustion tests of cladding materials.

e. $\quad$ After incident 5 (2009): 
- Recommended that sprinkler systems be fitted.

- Revision of Approved Document B.

- Revision of the stay-put policy.

It is clear from the above-mentioned list of incident cases and recommendations that the standard policy of "stay put" needs to be fundamentally revisited, and that there is a clear need to investigate changes and amendments in laws and regulations, such as Approved Document B, which is clearly an "elephant-in-the-room" case. These two case studies, coupled with the theoretical underpinning of the black elephant and black swan phenomena, and using two techniques for root case analysis and assessment of vulnerabilities in the system, have demonstrated how they can be embedded in Masters training programmes that are targeted towards practitioners involved in the fields of safety and risk management.

\section{Conclusions}

Major events such as Grenfell Tower and Hurricane Katrina disasters provide major opportunities for learning from disasters, especially with regard to investigation and improvement. In this paper, we have discussed the causes of both disasters, with evidence from reports showing that the most crucial failure points can be attributed to evacuation and emergency response activities. The existing body of knowledge indicates that the most dominant approach to failure investigation and crisis management within the industry creates a dichotomy, by either separately focusing on core engineering or core management failures, which we have found to be an obstruction to effective learning. Through a combination of reliability engineering and crisis management concepts, we examined the similarities and differences between the two case studies in an attempt to develop a harmonized practice-based learning framework for designers, failure analysts, and first responders, as well as risk and crisis managers.

Graphical representation tools such as FTA, RBD and BS-BE, which cross over between various facets of engineering and management fields, provide a platform for better and faster analysis, which in turn enables policymakers and crisis management teams to deliver crucial decisions within the shortest possible time. In addition, they act like a mental visual model that summarises, and better presents, many pages of narratives, which is often a common feature in many incidents enquiry reports. Besides the ease of application of the tools combined in this study, it is believed that this fusion could potentially enhance the lead time for response during crisis because investigation and risk evaluation activities often account for significant amounts of decision-making time. These two case studies emphasize the need for a more divergent approach to incident investigation and general crisis management, especially when they involve a low probability of occurrence events. It is hoped that the findings of this study will help shift the paradigm of competence development in failure investigation and crisis management.

Author Contributions: Conceptualization, M.I.-M., S.H.-D. and A.L.; methodology, M.I.-M., S.H.-D. and A.L.; validation, S.H.-D., A.L. and A.Y.-K.; formal analysis, M.I.-M.; investigation, M.I.-M.; data curation, M.I.-M.; writing—original draft preparation, M.I.-M.; writing—review and editing, S.H.-D., A.L. and A.Y.-K.; supervision, S.H.-D. and A.L. All authors have read and agreed to the published version of the manuscript.

Funding: No funding.

Data Availability Statement: Not applicable.

Conflicts of Interest: The authors declare no conflict of interest.

\section{References}

1. Pradhan, N.S.; Das, P.J.; Gupta, N.; Shrestha, A.B. Sustainable Management Options for Healthy Rivers in South Asia: The Case of Brahmaputra. Sustainability 2021, 13, 1087. [CrossRef]

2. Sen, M.K.; Dutta, S.; Kabir, G. Flood resilience of housing infrastructure modeling and quantification using a bayesian belief network. Sustainability 2021, 13, 1026. [CrossRef] 
3. Rosa, A.; Santangelo, A.; Tondelli, S. Investigating the integration of cultural heritage disaster risk management into urban planning tools. The Ravenna case study. Sustainability 2021, 13, 872. [CrossRef]

4. Kuhlman, T.; Farrington, J. What is sustainability? Sustainability 2010, 2, 3436-3448. [CrossRef]

5. Lacey, A.W.; Chen, W.; Hao, H.; Bi, K. Structural response of modular buildings-An overview. J. Build. Eng. 2018, 16, 45-56. [CrossRef]

6. Müller, P.; Novák, J.; Holan, J. Destructive and non-destructive experimental investigation of polypropylene fibre reinforced concrete subjected to high temperature. J. Build. Eng. 2019, 26, 100906. [CrossRef]

7. McEwen, L.; Holmes, A.; Quinn, N.; Cobbing, P. ‘Learning for resilience': Developing community capital through flood action groups in urban flood risk settings with lower social capital. Int. J. Disaster Risk Reduct. 2018, 27, 329-342. [CrossRef]

8. Borell, J.; Eriksson, K. Learning effectiveness of discussion-based crisis management exercises. Int. J. Disaster Risk Reduct. 2013, 5, 28-37. [CrossRef]

9. Tan, J.-S.; Elbaz, K.; Wang, Z.-F.; Shen, J.S.; Chen, J. Lessons learnt from bridge collapse: A view of sustainable management. Sustainability 2020, 12, 1205. [CrossRef]

10. Mohamed, I.F.; Edwards, D.J.; Mateo-Garcia, M.; Costin, G.; Thwala, W.D.D. An investigation into the con-struction industry's view on fire prevention in high-rise buildings post Grenfell. Int. J. Build. Pathol. Adapt. 2019, 38, 451-471. [CrossRef]

11. Nguyen, K.; Mendis, P.; Fernando, S. Novel modelling approach for evacuation strategies of tall towers-A case study of Lotus Tower. J. Build. Eng. 2019, 25, 100763. [CrossRef]

12. Kim, K.; Bui, L. Learning from Hurricane Maria: Island ports and supply chain resilience. Int. J. Disaster Risk Reduct. 2019, 39, 101244. [CrossRef]

13. Labib, A.; Hadleigh-Dunn, S.; Mahfouz, A.; Gentile, M. Operationalizing learning from rare events: Framework for middle humanitarian operations managers. Prod. Oper. Manag. 2019, 28, 2323-2337. [CrossRef]

14. Boonmee, C.; Arimura, M.; Asada, T. Facility location optimization model for emergency humanitarian logistics. Int. J. Disaster Risk Reduct. 2017, 24, 485-498. [CrossRef]

15. Saleh, J.H.; Pendley, C.C. From learning from accidents to teaching about accident causation and prevention: Multidisciplinary education and safety literacy for all engineering students. Reliab. Eng. Syst. Saf. 2012, 99, 105-113. [CrossRef]

16. Dahl, Ø.; Kongsvik, T. Safety climate and mindful safety practices in the oil and gas industry. J. Saf. Res. 2018, 64, 29-36. [CrossRef]

17. Brown, G.D.; Corbet, S.; McMullan, C.; Sharma, R. Do industrial incidents in the chemical sector create equity market contagion? J. Saf. Res. 2015, 55, 115-119. [CrossRef] [PubMed]

18. Wu, D.; Yang, L.-C.; Wu, S.-S. Crisis management of SARS in a hospital. J. Saf. Res. 2004, 35, 345-349. [CrossRef] [PubMed]

19. Will, K.E.; Geller, E.S. Increasing the safety of children's vehicle travel: From effective risk communication to behavior change. J. Safety Res. 2004, 35, 263-274. [CrossRef]

20. DeJoy, D.M.; Smith, T.D.; Dyal, M.-A. Safety climate and firefighting: Focus group results. J. Saf. Res. 2017, 62, 107-116. [CrossRef]

21. Bundy, J.; Pfarrer, M.D.; Short, C.E.; Coombs, W.T. Crises and crisis management: Integration, interpretation, and research development. J. Manag. 2016, 43, 1661-1692. [CrossRef]

22. Levitt, B.; March, J.G. Organizational learning. Annu. Rev. Sociol. 1988, 14, 319-340. [CrossRef]

23. Toft, B.; Reynolds, S. Learning from Disasters, 2nd ed.; Perpetuity Press: Leicester, UK, 1997.

24. Fowler, T. Spill Response Compared to Apollo 13 Effort; Houston Chronicle: Houston, TX, USA, 2010.

25. Labib, A.; Read, M. A hybrid model for learning from failures: The Hurricane Katrina disaster. Expert Syst. Appl. 2015, 42, 7869-7881. [CrossRef]

26. Bigley, G.A.; Roberts, K.H. The incident command system: High-reliability organizing for complex and volatile task environments. Acad. Manag. J. 2001, 44, 1281-1299.

27. Gephart, R.P.; Van Maanen, J.; Oberlechner, T. Organizations and risk in late modernity. Organ. Stud. 2009, 30, 141-155. [CrossRef]

28. Pearson, C.M.; Clair, J.A. Reframing crisis management. Acad. Manag. Rev. 1998, 23, 59-76. [CrossRef]

29. Perrow, C. Normal Accidents: Living with High-Risk Technologies; Princeton University Press: Princeton, NJ, USA, 1984.

30. Starbuck, W.H.; Milliken, F.J. Challenger: Fine-tuning the odds until something breaks. J. Manag. Stud. 1988, 25, 319-340. [CrossRef]

31. Bundy, J.; Pfarrer, M.D.; Grodal, S.; Gotsopoulos, A.; Suarez, F. A burden of responsibility: The role of social approval at the onset of a crisis. Acad. Manag. Rev. 2015, 40, 345-369. [CrossRef]

32. Coombs, W.T. Protecting organization reputations during a crisis: The development and application of situa-tional crisis communication theory. Corp. Reput. Rev. 2007, 10, 163-176. [CrossRef]

33. Elsbach, K.D.; Sutton, R.I.; Principe, K.E. Averting expected controversies through anticipatory impression management: A study of hospital billing. Organ. Sci. 1998, 9, 68-86. [CrossRef]

34. Pfarrer, M.D.; DeCelles, K.A.; Smith, K.G.; Taylor, M.S. After the fall: Reintegrating the corrupt organization. Acad. Manag. Rev. 2008, 33, 730-749. [CrossRef]

35. McDonald, F.; Horwell, C.J.; Wecker, R.; Dominelli, L.; Loh, M.; Kamanyire, R.; Ugarte, C. Facemask use for community protection from air pollution disasters: An ethical overview and framework to guide agency decision making. Int. J. Disaster Risk Reduct. 2020, 43, 101376. [CrossRef] 
36. Yunusa-Kaltungo, A.; Labib, A. A hybrid of industrial maintenance decision making grids. Prod. Plan. Control. 2020, 26, 1-18. [CrossRef]

37. Appoh, F.; Yunusa-Kaltungo, A.; Sinha, J.K. Hybrid dynamic probability-based modeling technique for rolling stock failure analysis. IEEE Access 2020, 8, 182376-182390. [CrossRef]

38. Ayu, K.; Yunusa-Kaltungo, A. A holistic framework for supporting maintenance and asset management life cycle decisions for power systems. Energies 2020, 13, 1937. [CrossRef]

39. Iheukwumere-Esotu, L.; Yunusa Kaltungo, A. Assessment of barriers to knowledge and experience transfer in major maintenance activities. Energies 2020, 13, 1721. [CrossRef]

40. O'Brien, S.; Federici, F.; Cadwell, P.; Marlowe, J.; Gerber, B. Language translation during disaster: A comparative analysis of five national approaches. Int. J. Disaster Risk Reduct. 2018, 31, 627-636. [CrossRef]

41. March, J.G. Exploration and exploitation in organizational learning. Organ. Sci. 1991, 2, 71-87. [CrossRef]

42. Farjoun, M. Beyond dualisim: Stability and change as a duality. Acad. Manag. Rev. 2010, 35, $202-225$.

43. D'Adderio, L. The performativity of routines: Theorising the influence of artefacts and distributed agencies on routines dynamics. Res. Policy 2008, 37, 769-789. [CrossRef]

44. Feldman, M.S.; Pentland, B.T. Reconceptualizing organizational routines as a source of flexibility and change. Adm. Sci. Q. 2003, 48, 94. [CrossRef]

45. Latour, B. Visualization and cognition. Knowl. Soc. 1986, 6, 1-40.

46. Levinthal, D.A.; Rerup, C. Crossing an apparent chasm: Bridging mindful and less mindful perspectives on or-ganizational learning. Organ. Sci. 2006, 17, 502-513. [CrossRef]

47. Nonaka, I.; Takeuchi, H. The Knowledge-Creating Company; Oxford University Press: New York, NY, USA, 1995.

48. Haack, A. Fire protection in traffic tunnels-Initial findings from large-scale tests. Tunn. Undergr. Space Technol. 1992, 7, 363-375. [CrossRef]

49. Dell'Olio, L.; Ibeas, A.; Barreda, R.; Sañudo, R. Passenger behavior in trains during emergency situations. J. Saf. Res. 2013, 46, 157-166. [CrossRef]

50. Rådbo, H.; Svedung, I.; Andersson, R. Suicides and other fatalities from train-person collisions on Swedish railroads: A descriptive epidemiologic analysis as a basis for systems-oriented prevention. J. Saf. Res. 2005, 36, 423-428. [CrossRef] [PubMed]

51. Weick, K.E.; Sutcliffe, K.M. Managing the Unexpected: Resilient Performance in an Age of Uncertainty, 2nd ed.; Jossey-Bass: San Francisco, CA, USA, 2007.

52. Agwu, A.E.; Labib, A.; Hadleigh-Dunn, S. Disaster prevention through a harmonized framework for high reliability organisations. Saf. Sci. 2019, 111, 298-312. [CrossRef]

53. de Wit, P.A.; Cruz, R.M. Learning from AF447: Human-machine interaction. Saf. Sci. 2019, 112, 48-56. [CrossRef]

54. Markman, A.B.; Maddox, W.T.; Worthy, D.A. Choking and excelling under pressure. Psychol. Sci. 2006, 17, 944-948. [CrossRef]

55. Labib, A. Learning from Failures: Decision Analyses of Major Disasters; Butterworth Heinemann: London, UK, 2014.

56. Winstone, P. The aftermath of the Grenfell Tower fire and its relevance for construction project team members. J. Build. Surv. Apprais. Valuat. 2018, 6, 372-379.

57. Watt, R.G. Grenfell Tower fire-A tragic case study in health inequalities. Br. Dent. J. 2017, 223, 478. [CrossRef]

58. Smith, I. Has Grenfell Tower Had an Effect on UK House Building? The Independent: London, UK, 2018.

59. World Health Organisation (WHO). The World Health Report, 2004: Changing History. 2004. Available online: https: / /apps. who.int/iris/bitstream/handle/10665/42891/924156265X.pdf (accessed on 11 February 2021).

60. Jonsson, A.; Bonander, C.; Nilson, F.; Huss, F. The state of the residential fire fatality problem in Sweden: Epi-demiology, risk factors, and event typologies. J. Saf. Res. 2017, 62, 89-100. [CrossRef]

61. Jonsson, A.; Bergqvist, A.; Andersson, R. Assessing the number of fire fatalities in a defined population. J. Saf. Res. 2015, 55, 99-103. [CrossRef]

62. Mulvaney, C.; Kendrick, D.; Towner, E.; Brussoni, M.; Hayes, M.; Powell, J.; Robertson, S.; Ward, H. Fatal and non-fatal fire injuries in England 1995-2004: Time trends and inequalities by age, sex and area deprivation. J. Public Health 2009, 1, 31154-31161. [CrossRef] [PubMed]

63. Tannous, W.K.; Whybro, M.; Lewis, C.; Ollerenshaw, M.; Watson, G.; Broomhall, S.; Agho, K.E. Using a cluster randomized controlled trial to determine the effects of intervention of battery and hardwired smoke alarms in New South Wales, Australia: Home fire safety checks pilot program. J. Saf. Res. 2016, 56, 23-27. [CrossRef] [PubMed]

64. Gangolells, M.; Casals, M.; Forcada, N.; Roca, X.; Fuertes, A.; Roca-Ramon, X. Mitigating construction safety risks using prevention through design. J. Saf. Res. 2010, 41, 107-122. [CrossRef]

65. Hayes, J. Disaster incubation: Grenfell Tower's unnecessary lessons. Constr. Res. Innov. 2017, 8, 76-79. [CrossRef]

66. Seidu, R.D.; Robinson, H.; Young, B. Cost of Fire in Highrise Building. In Proceedings of the International Conference on Professionalism and ethics in Construction, 21 November 2018; Available online: https://openresearch.lsbu.ac.uk/item/868q2 (accessed on 12 February 2021).

67. American Society of Civil Engineers (ASCE). The New Orleans Hurricane Protection System: What Went Wrong and Why. 2007. Available online: http:/ / www.slfpae.com/studies/ASCE\%20External\%20Peer\%20Review\%20(Katrina).pdf (accessed on 11 February 2021). 
68. Crowther, K.G.; Haimes, Y.Y.; Taub, G. Systemic valuation of strategic preparedness through application of the inoperability input-output model with lessons learned from hurricane katrina. Risk Anal. 2007, 27, 1345-1364. [CrossRef]

69. Yunusa-Kaltungo, A.; Kermani, M.M.; Labib, A. Investigation of critical failures using root cause analysis methods: Case study of ASH cement PLC. Eng. Fail. Anal. 2017, 73, 25-45. [CrossRef]

70. Zhou, X.; Wang, L.; Qin, J.; Chai, J.; Muñoz, C.Q. Emergency rescue planning under probabilistic linguistic information: An in-tegrated FTA-ANP method. Int. J. Disaster Risk Reduct. 2019, 37, 101170. [CrossRef]

71. Li, Q.; Long, R.; Chen, H.; Geng, J. Low purchase willingness for battery electric vehicles: Analysis and simulation based on the fault tree model. Sustainability 2017, 9, 809. [CrossRef]

72. Marhavilas, P.K.; Tegas, M.G.; Koulinas, G.K.; Koulouriotis, D.E. A joint stochastic/deterministic process with multi-objective decision making risk-assessment framework for sustainable constructions engineering projects-A case study. Sustainability 2020, 12, 4280. [CrossRef]

73. Cheung, C.M.; Yunusa-Kaltungo, A.; Ejohwomu, O.; Zhang, R.P. 15 Learning from failures (LFF). In Construction Health and Safety in Developing Countries; Routledge: London, UK, 2019.

74. Labib, A.; Harris, M. Learning how to learn from failures: The Fukushima nuclear disaster. Eng. Fail. Anal. 2015, 47, 117-128. [CrossRef]

75. Ronan, T.; Teeuw, R.M. London's burning: Integrating water flow rates and building types into fire risk maps. Int. J. Emerg. Serv. 2016, 5, 34-51. [CrossRef]

76. Taleb, N.N. The Black Swan: The Impact of the Highly Improbable; Penguin Books: London, UK, 2010.

77. Castles, F.G. Black swans and elephants on the move: The impact of emergencies on the welfare state. J. Eur. Soc. Policy 2010, 20, 91-101. [CrossRef]

78. Ponkin, I.V. “Black Swan” Event as Manifestation of Uncertainties in Public Administration. Mediterr. J. Soc Sci. 2019, 10, 9-15. [CrossRef]

79. Möller, N.; Wikman-Svahn, P. Black elephants and black swans of nuclear safety. Ethic Policy Environ. 2011, 14, 273-278. [CrossRef]

80. Werther, G.F. Improving finance and risk management foresight abilities: Growing past the 'black swan'mindset through integrative assessment. J. Risk Manag. Financ. Inst. 2017, 10, 353-364.

81. Crease, R.P. Critical Point: Black elephants. Phys. World 2015, 28, 19.

82. Bezdrob, M.; Brkić, S.; Bajramović, D.; Gram, M.; Burić, D. ‘Black Swans' in IT Projects-Myth or Reality. In Proceedings of the 9th International Conference "An Enterprise Odyssey-Managing Change to Achieve Quality Development”, Zagreb, Croatia, 23 May 2018.

83. Slovic, P. Perception of risk. Science 1987, 236, 280-285. [CrossRef] [PubMed]

84. Alexander, D.A.; Klein, S. First responders after disasters: A review of stress reactions, at-risk, vulnerability, and resilience factors. Prehosp. Disaster Med. 2009, 24, 87-94. [CrossRef] [PubMed]

85. Osofsky, H.J.; Osofsky, J.D.; Arey, J.; Kronenberg, M.E.; Hansel, T.; Many, M. Hurricane Katrina's first responders: The struggle to protect and serve in the aftermath of the disaster. Disaster Med. Public Health Prep. 2011, 5, S214-S219. [CrossRef]

86. Hackitt, J. Building a Safer Future. Independent Review of Building Regulations and Fire Safety: Interim Report. Presented to Parliament by the Secretary of State for Communities and Local Government by Command of Her Majesty, December 2017. 2017. Available online: www.gov.uk/government/publications (accessed on 11 February 2021).

87. Rowden, R.W.; Conine, C.T. The impact of workplace learning on job satisfaction in small US commercial banks. J. Workplace Learn. 2005, 17, 215-230. [CrossRef]

88. Postareff, L.; Lindblom-Ylanne, S. Variation in teacher's descriptions of teaching: Broadening the under-standing of teaching in higher education. Learn. Instr. 2018, 18, 109-120. [CrossRef]

89. Becher, T. The learning professions. Stud. High. Educ. 1996, 21, 43-56. [CrossRef]

90. Whitston, K. Key skills and curriculum reform. Stud. High. Educ. 1998, 23, 307-319. [CrossRef]

91. Kletz, T. Learning from Accidents; Butterworth-Heinmann: Oxford, UK, 2001.

92. Pick, A.M.; Begley, K.J.; Augustine, S. Changes in teaching strategies to accommodate a new generation of learner: A case study. Pharm. Educ. 2017, 17, 95-99.

93. Partridge, H.; Hallam, G. Educating the millenial generation for evidence based information practice. Libr. Hi-Tech. 2006, 24, 400-419. [CrossRef]

94. Sharp, L. Grand canyon university stealth learning: Unexpected learning opportunities through games. J. Instr. Res. 2012, 1, 42-48. [CrossRef]

95. Edwards, D.J. Types of case study work: A conceptual framework for case-based research. J. Humanist. Psychol. 1998, 38, 36-70. [CrossRef]

96. Uiboleht, K.; Karm, M.; Postareff, L. How do university teachers combine different approaches to teaching in a specific course? A qualitative multi-case study. Teach. High. Educ. 2016, 21, 1-16. [CrossRef]

97. Apostolakis, G. The concept of probability in safety assessments of technological systems. Science 1990, 250, 1359-1364. [CrossRef]

98. Bier, V.M.; Haimes, Y.Y.; Lambert, J.H.; Matalas, N.C.; Zimmerman, R. A survey of approaches for assessing and managing the risk of extremes. Risk Anal. 1999, 19, 83-94. [CrossRef]

99. Barach, P.; Small, S.D. Reporting and preventing medical mishaps: Lessons from non-medical near miss reporting systems. BMJ Br. Med. J. 2000, 320, 759. [CrossRef] [PubMed] 
100. Baum, J.A.; Dahlin, K.B. Aspiration performance and railroads' patterns of learning from train wrecks and crashes. Organ. Sci. 2007, 18, 368-385. [CrossRef]

101. Madsen, P.M.; Desai, V. Failing to learn? The effects of failure and success on organizational learning in the global orbital launch vehicle industry. Acad. Manag. J. 2010, 53, 451-476. [CrossRef]

102. Lant, T.K.; Argote, L. Organizational learning: Creating, retaining, and transferring knowledge. Adm. Sci. Q. 2000, 45, 622. [CrossRef]

103. Balogun, J.; Johnson, G. Organizational restructuring and middle manager sensemaking. Acad. Manag. J. 2004, 47, 523-549.

104. Beck, T.E.; Plowman, D.A. Experiencing rare and unusual events richly: The role of middle managers in ani-mating and guiding organizational interpretation. Organ. Sci. 2009, 20, 909-924. [CrossRef]

105. Labib, A. Learning (and unlearning) from failures: 30 years on from bhopal to fukushima an analysis through re-liability engineering techniques. Process Saf. Environ. Prot. 2015, 97, 80-90. [CrossRef]

106. Dash, A.; Bhattacharjee, R.; Paul, P.; Bhattcharjee, R. Lessons learnt from Indian inundation disasters: An analysis of case studies. Int. J. Disaster Risk Reduct. 2016, 20, 93-102. [CrossRef]

107. BBC2. Grenfell Tower: The Fires That Foretold the Tragedy. Available online: https://www.bbc.co.uk/news/uk-england-459828 10 (accessed on 1 November 2018). 